\title{
THERMAL COMFORT ASSESSMENT AT PARCEL AND LOGISTIC INDUSTRY: A FIELD STUDY IN MALAYSIA
}

(Date received:22.6.10/Date approved:21.5.11)

\author{
Ahmad Rasdan Ismail ${ }^{1}$, Norfadzilah Jusoh², \\ Mohd. Nizam Ab. Rahman ${ }^{3}$, Rozli Zulkifli ${ }^{2}$ and Kumaran Kardigama ${ }^{4}$ \\ ${ }^{1,2,3}$ Faculty of Mechanical Engineering, Universiti Malaysia Pahang, \\ 26600 Pekan, Pahang \\ ${ }^{4}$ Department of Mechanical and Materials Engineering, Faculty of Engineering and Built Environment, \\ Universiti Kebangsaan Malaysia, 43600 UKM Bangi, Selangor \\ Email: ${ }^{1}$ arasdan@gmail.com/rasdan@ump.edu.my
}

\section{ABSTRACT}

This paper presents the workers thermal sensation votes and perception of the thermal environment in air conditioning at one of the workspace in Malaysian parcel and logistic industry. The environment factors examined was the relative humidity (\%), wind speed $(\mathrm{m} / \mathrm{s})$, air temperature $\left({ }^{\circ} \mathrm{C}\right)$ and $\mathrm{CO}_{2}(\mathrm{ppm})$ of the surrounding workstation area. These factors were measured using custom integrated thermal comfort apparatus namely as Thermal Comfort Equipment developed by Solar Energy Research Institute (SERI), Universiti Kebangsaan Malaysia, which is capable of measuring various environmental factors. The time series data of fluctuating level of environment factors were plotted to identify the significant changes and patterns among the factors. Then the thermal comfort of the workers was assessed by using ISO Standard 7730 and thermal sensation scale by using Predicted Mean Vote (PMV). Further Predicted Percentage Dissatisfied (PPD) is used to estimate the thermal comfort satisfaction of the occupant. Finally the PMV and PPD were plotted to present the thermal comfort scenario of workers involved in related workspace. The results revealed that the thermal comfort at the particular workplace was warming followed by thermal sensation and likely to be dissatisfied by dominant of occupants. The results also indicated that the CO${ }_{2}$ and index of clothing (clo) dominated the parameters of comfort to the occupants.

Keywords: Air Quality, PMV, PPD, Thermal Comfort

\subsection{INTRODUCTION}

It is a well known fact, that the environmental factors influence the performance of a human being in building which is mosque, school, office and industry. Thermal stress, high humidity and insufficient illumination are often the reason for the limitation of the ability to fulfill a certain task for occupant. But what about this situation fulfilled at a certain company? The limitation of processing this situation, is affecting the productivity of the company. If the decrease in productivity is lasting for a longer period, and many employees have to deal with these circumstances, the effect to the productivity can be enormous in the company. The research findings are restricted to the Malaysian workplace environment, where the awareness among workers on improving productivity is still low [1]. The condition of the environment factors of a company seems to be very important with respect to the productivity and hence the success

A number of studies have found that, Air-conditioned building: This has sealed windows and cooling is available at all times of the year. Space conditions are tightly controlled. In this case lowenergy design requires optimisation of the Heating Ventilation Air Conditioning (HVAC) plant, for example minimising the use of heating and cooling at the same time as fan power consumption. Typically, the air will also be subjected to particle filtration and humidity control [2].
In the notes of research by Feriadi et al. [3], explained that the effect of exposure to air conditioned environments on thermal comfort perception in naturally ventilated buildings in Singapore and Indonesia found for people exposed to air conditioned spaces for less than 4 hour and for more than 8 hour per day showed preferences for higher comfort temperatures. People with less than 4 hour/day exposure to air-conditioning, may have been acclimatised to the hot and humid environment [4]. People with longer exposure time to air-conditioning were thought to desire warmer temperatures after working inside an air-conditioning office all day [4]. The influence of metabolic changes on thermal sensation was examined through modified step-changes during the experiment [4]. High metabolic activities and even low metabolic activities, prior to an experiment, will affect thermal perceptions and preferences of humans [5]. When predicting thermal sensation, detailed descriptions of the activities during the past 15 min shall improve the precision of the vote predicting. Clothing adjustments are found to be one of the causal links between indoor thermal comfort and outdoor weather. Evidence from a cross-sectional study of clothing in Australia demonstrates that outdoor temperatures strongly influence clothing worn indoors and no correlation was found to prevailing indoor temperatures [6]. Feriadi et al. [3] suggested that a variable operational set point for air-conditioned buildings, programmed on the basis of 
a running-mean outdoor temperature would save HVAC energy, potentially increase thermal comfort, and accommodate varying clothing behaviors.

Thermal comfort is recognised as a key parameter for a healthy and productive workplace. Because of that, lowering energy use in commercial building is vital if a significant reduction in greenhouse gas emissions is to be achieved. Traditionally thermal comfort has been achieved at the expense of significant energy use for heating and/or cooling. In another major study, Taylor. P, et al. [7] found that a well-designed building should be able to provide good thermal comfort, while simultaneously having low energy consumption.

Thermal comfort can be defined as that condition of mind which expresses satisfaction with the thermal environment [8]. The reference to 'mind' indicates that it is essentially a subjective term; however, there has been extensive research in this area and a number of indices exist which can be used to assess environments for thermal comfort $[9,10]$. However Ibrahim et al. [11] suggested two conditions for comfort; they were that the body is in heat balance and that the mean skin temperature and sweat rate are within limits required for comfort. Conditions required for heat balance can be derived from a heat balance equation. Mean skin temperatures and sweat rates that are acceptable for comfort have been derived from empirical investigation [2].

Predicted Mean Vote (PMV) is a parameter for assessing thermal comfort in an occupied zone based on the conditions of metabolic rate, clothing, air speed besides temperature and humidity. PMV values refer the ASHRAE thermal sensation scale [2] that ranges from -3 to 3 as follows: $3=$ hot, $2=$ warm, $1=$ slightly warm, $0=$ neutral, $-1=$ slightly cool, $-2=$ cool, $-3=$ cold. Figure 1 summarises the overall process of using the six variables associated with thermal comfort sensation to evaluate the PMV [12]. The general comfort equation developed by Fanger [9] to describe the conditions under which a large group of people will feel in thermal neutrality is too complex and cannot be used in real time applications:

$$
\begin{aligned}
\text { PMV }= & \left(0.028+0.3033 \mathrm{e}^{-0.036 \mathrm{M}}\right)(\mathrm{M}-\mathrm{W})-3.05 \\
& {[5.733-0.000699(\mathrm{M}-\mathrm{W})-\mathrm{Pa}] } \\
& -0.42[(\mathrm{M}-\mathrm{W})-58.15]-0.0173 \\
& \mathrm{M}(5.867-\mathrm{Pa})-0.0014 \mathrm{M}\left(34-\mathrm{T}_{\mathrm{a}}\right) \\
& -3.96 \times 10^{-8} \mathrm{fcl}\left[\left(\mathrm{T}_{\mathrm{cl}}+273\right)^{4}-\left(\mathrm{T}_{\mathrm{mrt}}+273\right)^{4}\right] \\
& \left.-\mathrm{fcl} . \mathrm{hc}\left(\mathrm{T}_{\mathrm{cl}}-\mathrm{T}_{\mathrm{a}}\right)\right\}
\end{aligned}
$$

Where:

$$
\begin{aligned}
\mathrm{T}_{\mathrm{cl}}= & 35.7-0.028(\mathrm{M}-\mathrm{W}) \\
& -0.155 \mathrm{I}_{\mathrm{cl}}\left[3.96 \times 10^{-3} \mathrm{fcl}\left[\left(\mathrm{T}_{\mathrm{cl}}+273\right)^{4}\right.\right. \\
& \left.-\left(\mathrm{T}_{\mathrm{mrt}}+273\right)^{4}\right]-\mathrm{fcl} . \mathrm{hc}\left(\mathrm{T}_{\mathrm{cl}}-\mathrm{T}_{\mathrm{a}}\right) \\
\mathrm{h}_{\mathrm{c}}= & \left\{\begin{array}{l}
2.38\left(\mathrm{~T}_{\mathrm{cl}}-\mathrm{T}_{\mathrm{a}}\right)^{0.25} \text { for } 2.38\left(\mathrm{~T}_{\mathrm{cl}}+\mathrm{T}_{\mathrm{a}}\right)^{0.25} \geq 12.1 \sqrt{\mathrm{V}_{\text {air }}} \\
12.1 \sqrt{\mathrm{V}_{\text {air }}} \text { for } 2.38\left(\mathrm{~T}_{\mathrm{cl}}-\mathrm{T}_{\mathrm{a}}\right)^{0.25} \leq 12.1 \sqrt{\mathrm{V}_{\text {air }}}
\end{array}\right.
\end{aligned}
$$

The parameters are defined as follows:

$$
\begin{array}{ll}
\mathrm{PMV} & =\text { Predicted mean vote } \\
\mathrm{M} & =\text { Metabolism }\left(\mathrm{W} \mathrm{m}^{2}\right) \\
\mathrm{W} & =\text { External work, equal to zero for most activity }\left(\mathrm{W} \mathrm{m}^{2}\right) \\
\mathrm{I}_{\mathrm{cl}} & =\text { Thermal resistance of clothing }(\mathrm{Clo})
\end{array}
$$

$\mathrm{f}_{\mathrm{cl}} \quad=$ Ratio of body's surface area when fully clothed to body's surface area when nude

$\mathrm{T}_{\mathrm{a}}=$ Air temperature $\left({ }^{\circ} \mathrm{C}\right)$

$\mathrm{T}_{\text {mrt }}^{\mathrm{a}}=$ Mean radiant temperature $\left({ }^{\circ} \mathrm{C}\right)$

$\mathrm{V}_{\text {air }} \quad=$ Relative air velocity $\left(\mathrm{m} \mathrm{sec}^{1}\right)$

$\mathrm{P}_{\mathrm{a}} \quad=$ Partial water vapor pressure $(\mathrm{Pa})$

$\mathrm{h}_{\mathrm{c}}^{\mathrm{a}}=$ Convectional heat transfer coefficient (W m² K)

$\mathrm{T}_{\mathrm{cl}}=$ Surface temperature of clothing $\left({ }^{\circ} \mathrm{C}\right)$

Furthermore, the equation for PPD is given as follows:

$$
\mathrm{PPD}=100-95 \exp \left(-0.03353 \mathrm{PMV}^{4}+0.2179 \mathrm{PMV}^{2}\right)
$$

Predicted Percentage Dissatisfied (PPD) is used to estimate the thermal comfort satisfaction of the occupant. It is considered that satisfying $80 \%$ of occupant is good: That is, PPD less than $20 \%$ is good [13].

Improving worker's productivity, occupational health and safety are major concerns of industry, especially in developing countries. However, these industries are featured with improper workplace design, ill-structured jobs, mismatch between worker's abilities and job demands, adverse environment, poor humanmachine system design and inappropriate management programs [14]. Light, noise, air quality and the thermal environment were considered factors that would influence the acceptability and performance on the occupants of premises. ISO 7730 [15] stated that lower emotional health is manifested as psychological distress, depression and anxiety, whereas lower physical health is manifested as heart disease, insomnia, headaches and infections. These health problems could lead to organisational symptoms such as job dissatisfaction, absenteeism and poor work quality. Irritated, sore eyes and throat, hoarseness, stuffy congested nose, excessive mental fatigue, headache and unusual tiredness were all signs of the negative workplace environmental conditions [9].

At this stage, the study is focused on examine thermal comfort and air quality for occupants at workstation in parcel and logistics industry.

\subsection{MATERIALS AND METHODS}

The field study was conducted in one of the Malaysian parcel and logistic industry. This company principal activity is providing courier service covered peninsular Malaysia as well as Sabah and Sarawak. It meets the demand for fast, efficient and reliable service for the speedy transfer of light-weight and high value goods between locations. To date it has a total of 180 networks, comprising of branches and agents all over Malaysia, Singapore and Brunei Darussalam. The exact location of study was at printing department where the size of the operation rooms $8 \mathrm{~m} \mathrm{x}$ $10 \mathrm{~m}$. It consists:

i) 6 unit of printing machine with high performance but only 2 printing machines work.

ii) 4 unit of desktop computer.

iii) 2 ventilation fans but only 1 unit work.

iv) 2 units of air conditioner as main air ventilation in the section.

v) 8 units of table and chair.

The rooms also include a side for consignment note storage. There are about 3 people working inside this section. The layout plan for location of study as illustrated in Figure 1. 


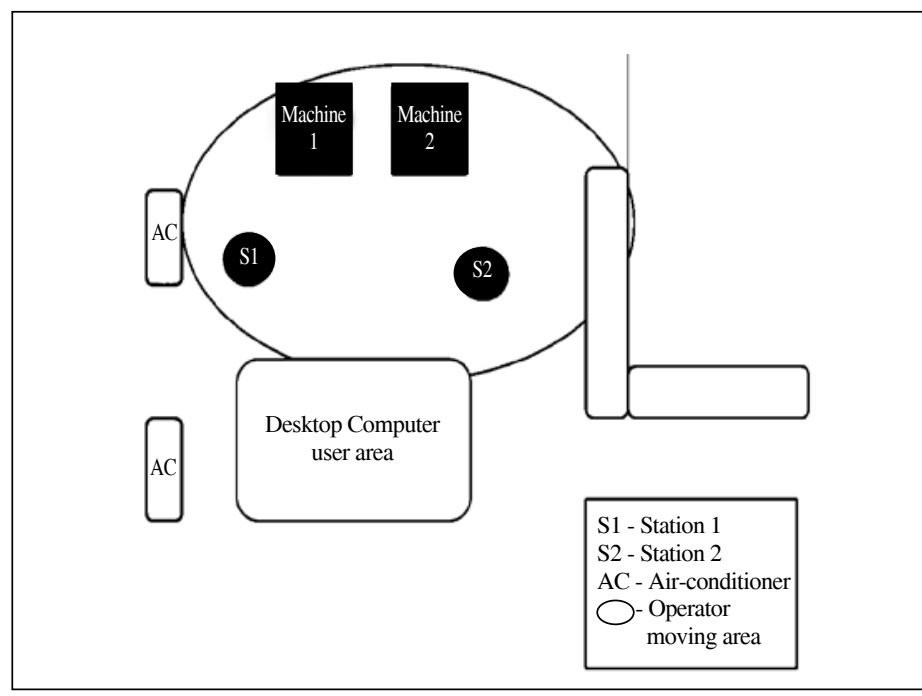

Figure 1: Layout plan of workstation area

\section{Subject and Work Schedule}

Only one 24 years old male operator involved in operating the printing machine. The measurement of thermal comfort was carried out between 9.30 am to $1.30 \mathrm{pm}$. The system operation procedures for printing machine are as follows:

i) One operator operate two printing machine simultaneously

ii) Operator will fill the consignment note for printing in the print case on both machine as shown as in Figure 3

iii) One print case can contain 300 consignment note to print

iv) Then, operator need to pick out the printed consignment note repeatedly and put it on the desk for next task

v) After that, operator need to refill the consignment note in the print case repeatedly.

\section{Measurement of Indoor Climates}

Thermal parameters at workstations were measured with Thermal Comfort Equipment as shown as Figure 2 for measuring air temperature, air velocity, and relative humidity. In addition, as the floor surface temperature and radiant temperature asymmetry may affect occupant thermal sensations. The air conditioning was operated during measurement. Figure 3 shows operators perform their work which is to fill the consignment note for print in the print case on both machines.

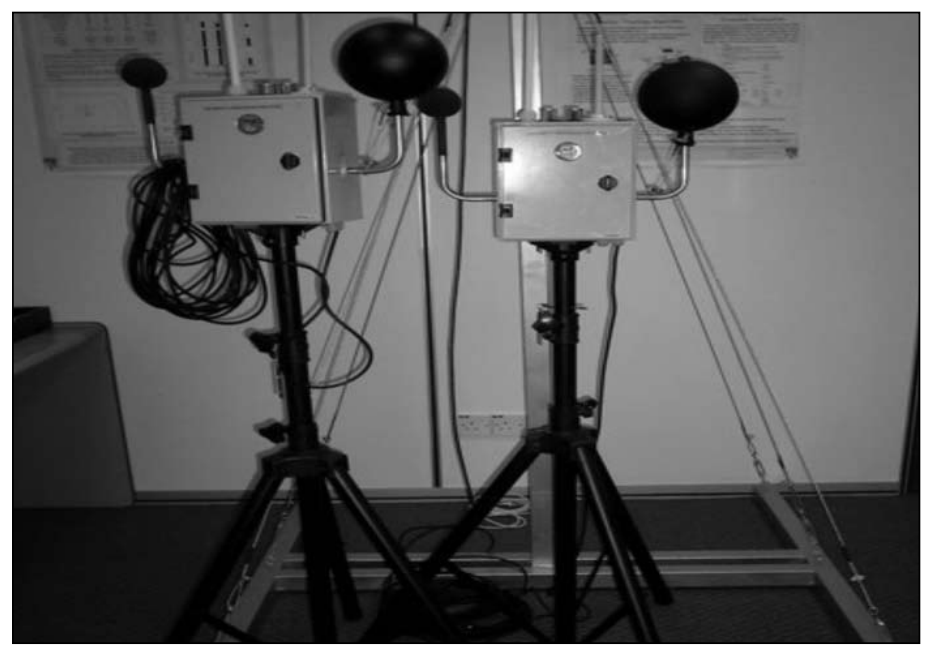

Figure 2: Thermal comfort equipment

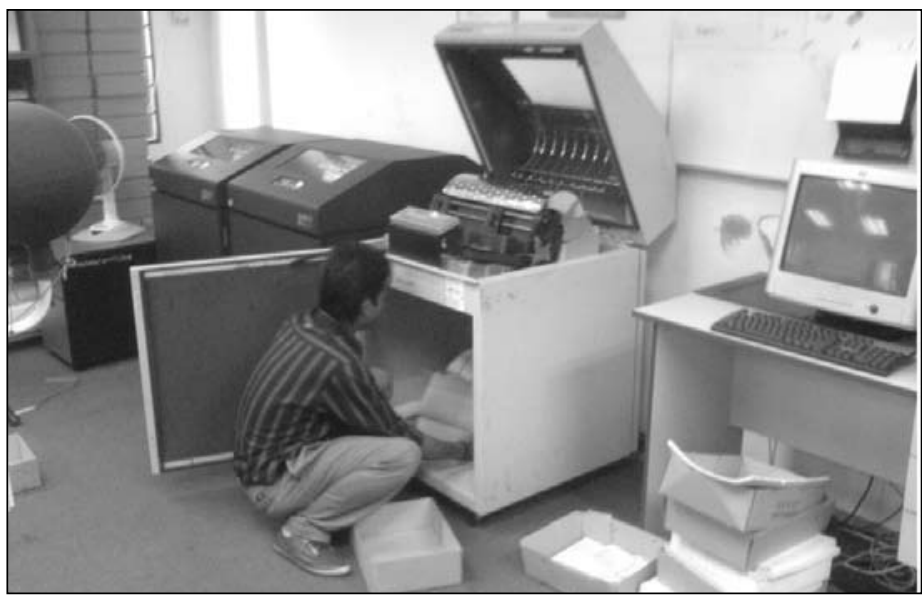

Figure 3: An operator fill-up the consignment note for print in the print case for two machines

\subsection{RESULT AND DISCUSSION}

This section will discussed the finding from this particular exercise. Thermal comfort parameters are examined, with exploration of the physical parameters such as air temperature, wind speed and humidity. All these data are correlated with the results of the assessment of thermal comfort and health as perceived by the occupants. The air temperature in this station was around $30^{\circ} \mathrm{C}$ to $31.1^{\circ} \mathrm{C}$. As in Figure 4, the graph shows that there has been not steady increase temperature in workplace. A small drop can be noticed every hour during measurement. The intrinsic clothing insulation was calculated from respondent clothing checklist according to ISO 7730. These stations were operated by workers, wearing shirts with short sleeves, trousers, socks, shoes, underpants and the work was only rated as sedentary activity (office). The according values are 1.6 met and 1.0 Clo. Hence the metabolic rate is $93 \mathrm{~W} / \mathrm{m}^{2}$. The metabolic rate was estimated based on respondent checklist activities.

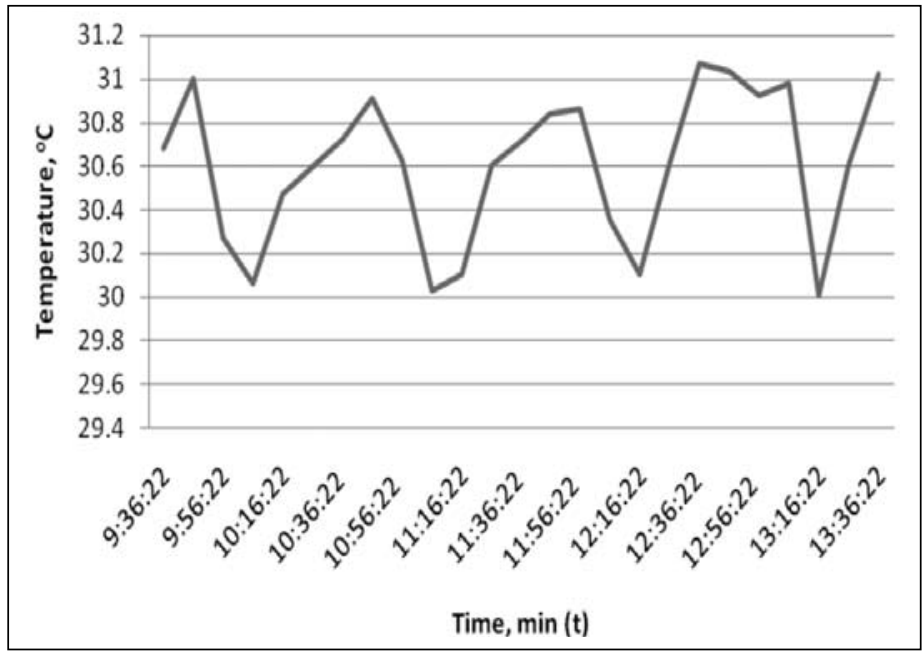

Figure 4: Air temperature measured at the workplace

The results obtained from the preliminary analysis of wind speed are presented in Figure 5. In Figure 5 there is clear trend increasing at the beginning measurement and after that the data of wind speed decrease. At intervals wind speed increase again. From this data, the higher wind speed at 11.56 am was $0.5 \mathrm{~m} / \mathrm{s}$. 


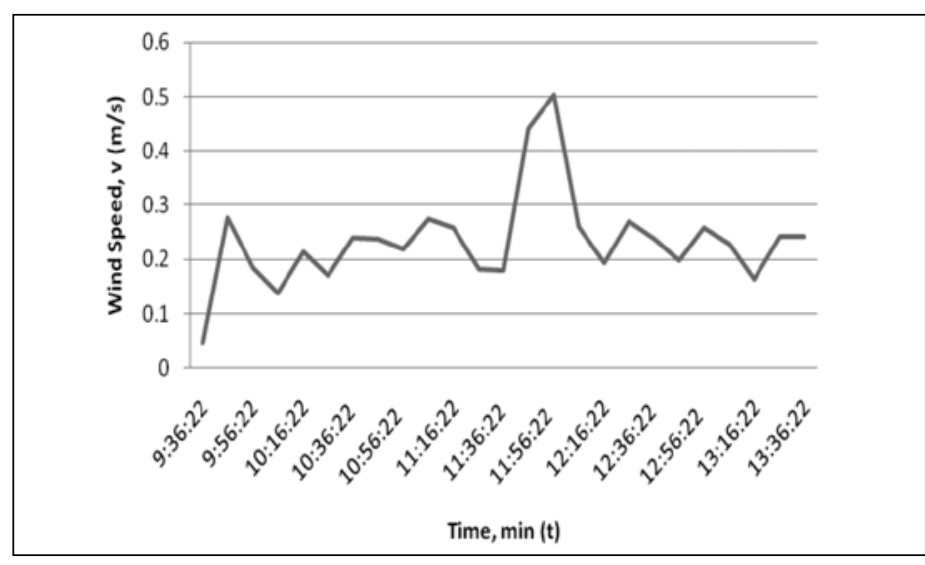

Figure 5: Wind speed measured at the workplace

Figure 6 shows the humidity decreases consistently throughout the day. Starting at around $57 \%$ relative humidity, the tendency is decreasing. At 13:36 pm the humidity increases to $46 \%$ during measurement finish.

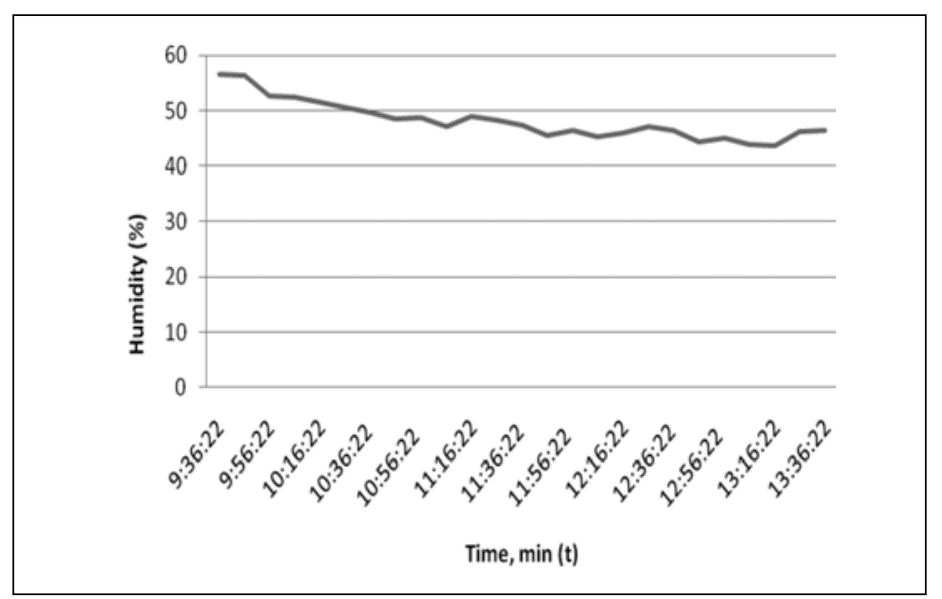

Figure 6: Relative humidity measured at the workplace

A statistical summary of overall thermal comfort indices is presented in Figure 7. The day measurement started sunny and dry. However, the influence of the outside environment is very strong. Figure 7 shows Predicted percentage of dissatisfied (PPD) as a function of predicted mean vote (PMV). The result illustrated the station PMV index were 1.8 to 2 , indicating slightly warm to warm. Meanwhile, the PPD is around $67 \%$ to $78 \%$.

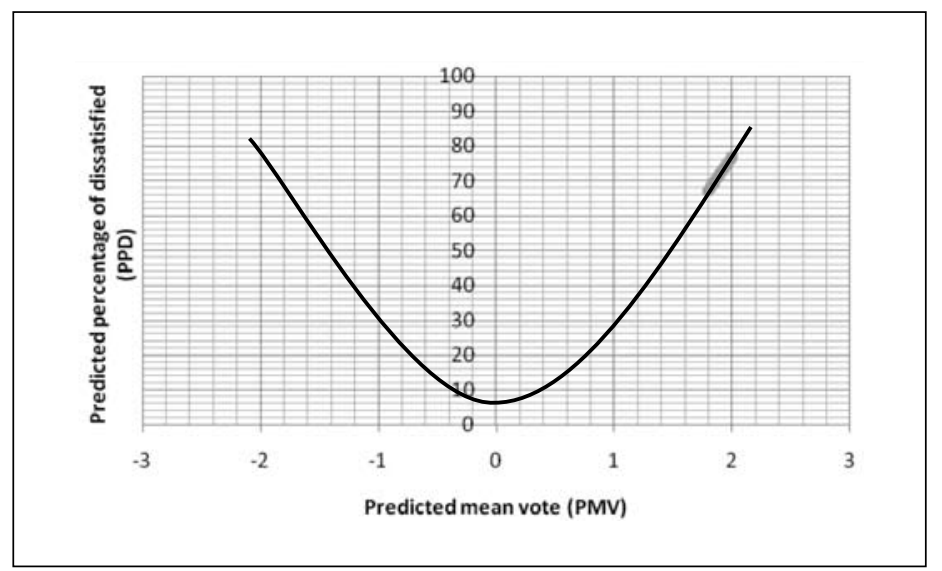

Figure 7: Predicted percentage of dissatisfied (PPD) as a function of predicted mean vote (PMV)

\subsection{DISCUSSIONS}

It is generally believed that when occupants have little control over space temperature, comfort conditions can be set using the theory developed by Fanger [9]. The important finding was that this building usually has a central fan, or local fans but also have mechanical cooling systems, that provide the ventilation [16]. The most interesting finding was that the high PPD and 2> PMV $>1.8$ as illustrated in Figure 7 is related to the indoor temperature and lower clothing insulation level.

The average air temperature in the workplace was $30^{\circ} \mathrm{C}$ compare to the standard value was 20 to $26^{\circ} \mathrm{C}$ for normal indoor area. The result of this study showed that this value is much higher than the standard value. The reason because influence the environment outside and probable therefore that the worker come in and out and also activities in the workplace. Another possible explanation for this is that the factor might be contributed to this phenomenon was the less air ventilation in the workplace. The reason is only one unit of ventilation fan work and need to be supported by two unit of medium horse power air conditioner.

Surprisingly, another factor contribute was the chemical reaction from the consignment note (carbon paper) storage. An implication of this is also the possibility that the workers have to wear shirts with short sleeves, shoes, shock, trouser and underpants. The clothes and activity might be a reason for stronger impression of the temperature.

The PMV model can only be used for predicted whole body mean thermal sensation. Following McIntyre [17], thermal sensations voted higher than 1.5 was treated as "dissatisfied with thermal environments". From inspection of the data, it appears that almost all occupants' dissatisfaction with the thermal environment resulted from general discomfort with overall thermal conditions, as the calculated PMV and PPD.

This study present because of decreasing wind speed will increase air temperature. This is because related with air quality $\left(\mathrm{CO}_{2}\right.$ from carbon paper). Actually, the occupants made comments relating air movement to air freshness, supporting this explanation. This study results show that occupants may be averse to thermal environments with very low wins speed. Zhang et al. [18] found that office workers had a strong general preference for higher wind speed rates and suggested that upper limits on wind speed be relaxed. Further investigation should be undertaken to determine whether low-end wind speeds should be introduced.

\subsection{CONCLUSIONS}

Returning to the aim posed at the beginning of this study, it is now possible to state that scale for sensation vote for PMV was warm which ranging from 1.8 to 2 . The following conclusions can be drawn from the present study that $67 \%$ to $76 \%$ was likely to be dissatisfied by the occupant in the workspace. This study indicated that this place was not comfort for occupant. An implication of this is the possibility that the thermal comfort of a factory worker depends on the average skin temperature (resulting from the combination of climate, clothing and metabolic heat production). 


\section{REFERENCES}

[1] Ismail A.R., Abdul Rani M.R., Mohd. Makhbul Z.K., A. Rahman M.N., and Deros B.M. (2009). Modelling of Workers' Productivity Using Environmental Parameters in Malaysian Electronic Industry. Journal - The Institution of Engineers, Malaysia, 70(1).

[2] Holmes, M.J. and Hacker, J.N. (2007). Climate Change, Thermal Comfort and Energy: Meeting the Design Challenges of the 21st Century. Energy and Buildings, 39: 802-814. DOI: 10.1016/j.enbuild.2007.02.009.

[3] Feriadi H, Wong, N.H., Chandra, S., Cheong, K.W., and Tham, K.W. (2002). Redefining Appropriate Thermal Comfort Standard for Naturally Ventilated Buildings in Tropics (Singapore and Indonesia perspective). In: Monterey Proceedings of the indoor air, P. 110-5.

[4] Chun C, Kwok, A., Mitamura, T., Miva, N., and Tamura, A. (2008). Thermal Diary: Connecting TemperatureH to Indoor Comfort. Building and Environment, 43: 877-885. DOI: 10.1016/j.buildenv.2007.01.031.

[5] Goto T, Toftum, J., and Fanger, P.O. (2002). Thermal Sensation and Comfort with Transient Metabolic Rates. In: Monterey Preceedings of the indoor air, P. 1038-43.

[6] Morgan CA, deDear RJ and Brager GS. (2002) Climate Clothing and Adaptation in the Built Environment. In: Monterey Proceedings of the indoor air, P. 98-103.

[7] Taylor. P, Fuller, R.J., and Luther, M.B. (2008). Energy Use and Thermal Comfort in a Rammed Earth Office Building. Energy and Buildings, 40: 793-800. DOI: 10.1016/j. enbuild.2007.05.013.

[8] Ho, S.H., L. Rosario and M.M. Rahman. (2008). Thermal Comfort Enhancement by Using a Ceiling Fan. Applied Thermal Eng, 29: 1648-1656. DOI:10.1016/j. applthermaleng.2008.07.015
[9] Fanger, P.O. (1970). Thermal Comfort. Danish Technical Press, Copenhagen. ISBN: 0-07-019915-9, pp: 21-23.

[10] Shek, K.W. and W.T. Chan. (2008). Combined Comfort Model of Thermal Comfort and Air Quality on Buses in Hong Kong. Sci. Total Environ, 389: 277-282. http://www. ncbi.nlm.nih.gov/pubmed/17949792

[11] Ibrahim Atmaca, Omer Kaynakli and Abdulvahap Yigit (2007). Effects of Radiant Temperature on Thermal Comfort. Build. Environ, 42: 3210-3220. DOI: 10.1016/j. buildenv.2006.08.009

[12] American Society of Heating. (2005). ASHRAE HandbookFundamentals. Refrigerating and Air- Conditioning Engineers, Inc., Atlanta. ISBN: 1931862710

[13] Guan, Y., M. Hosni, B.W. Jones and T.P. Gielda. (2003). Literature Review of the Advances in Thermal Comfort Modeling. ASHRAE Trans, 109: 908-916.

[14] Roberto Z. Freire, Gustavo H. C. Oliveira and Nathan Mendes. (2008). Predictive Controllers for Thermal Comfort Optimization and Energy Savings. Energy Build, 40: 13531365. DOI: 10.1016/j.enbuild.2007.12.007

[15] ISO 7730. (1994). Moderate Thermal Environments: Determination of the PMV and PPD Indices and Specification of the Conditions for Thermal Comfort. http://www.cjwalsh.ie/tag/iso-7730-moderate-thermalenvironments-determination-of-the-pmv-and-ppd-indicesand-specification-of-the-conditions-for-thermal-comfort.

[16] Micheal J.H., and Jacob N.H. (2007). Climate Change, Thermal Comfort and Energy: Meeting the Design Challenge of the 21st century. Energy and Buildings, 49: 802-814. DOI: 10.1016/j.enbuild.2007.02.009

[17] McIntyre DA. (1980). Indoor Climate. London: Applied Science Publishers Ltd.

[18] Zhang H, Arens EA, Fard SA, Huizenga C, Paliaga G, and Brager G. (2007). Air Movement Preferences Observed in Office Buildings. International Journal of Biometeorology. 51(5): 349-60.

\section{PROFILES}

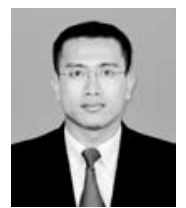

IR. AHMAD RASDAN BIN ISMAIL is a corporate member of IEM as well as professional engineer registered with the BEM. He holds a Bachelor Mechanical Engineering. (Hons) (UKM) and a M.Sc in Manufacturing Systems Engineering (UPM). He is currently a senior lecturer and head of industrial engineering programme at Faculty of Mechanical Engineering, Universiti Malaysia Pahang. His research interests include industrial ergonomics related to environmental ergonomics. He is also noise competent person registered under DOSH Malaysia and also a registered consultant for Noise and Vibration under DOE Malaysia.

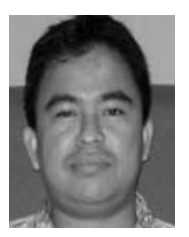

DR MOHD NIZAM AB RAHMAN is an associate professo in Quality and Operations Management at the Department of Mechanical and Materials Engineering, UKM. His research interests include quality operations, modern quality management such as supply chain, lean, Six sigma, Production SPC. He graduated in Industrial Physics in 1996 and obtained an MSc in 1999 from the Universiti Teknologi Malaysia as well as $\mathrm{PhD}$ in Quality and Operations and Operations Management from the University of Nottingham. He has been working as an $\mathrm{R} \& \mathrm{D}$ Engineer with Panasonic AVC Networks, and worked in Japan for a couple of years.

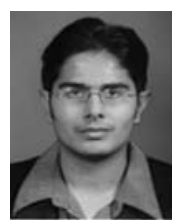

ENGR. KUMARAN KARDIGAMA is a lecturer and researcher at Faculty of Mechanical Engineering, University Malaysia Pahang. He was a Research Assistant at Mechanical Engineering Department, Universiti Tenaga Nasional. He graduated from University Tenaga Nasional and holds an M.Eng. (Mechanical Engineering) and B.Eng. (Honors) in Mechanical Engineering. He has an enormous experience in research work especially in advanced manufacturing technology, optimisation, artificial intelligent and nanomaterials. 